\title{
Preparation of an Amphoteric Lignin Copolymer and Its Value in the Papermaking Industry
}

\author{
Zhongming Liu, ${ }^{\mathrm{a}}$ Gao Chao, ${ }^{\mathrm{a}}$ Linlin Chen, ${ }^{\mathrm{a}}$ Xinyu Dong, ${ }^{\mathrm{a}}$ Fangong Kong, \\ Shoujuan Wang, ${ }^{\mathrm{a}, *}$ Magdi E. Gibrill, ${ }^{\mathrm{a}}$ Lucian Lucia, ${ }^{\mathrm{c}}$ and Pedram Fatehi ${ }^{\mathrm{d}}$
}

\begin{abstract}
Lignin biomass is an important renewable woody material that can be converted into high value-added products through physical and chemical reactions, such as paper strength additives. In this study, a cationic methacryloyloxyethyl trimethylammonium chloride monomer (DMC) and anionic acrylic monomer (AA) were grafted onto softwood kraft lignin through free radical polymerization to prepare an amphoteric lignin copolymer. Fourier transform infrared spectroscopy (FTIR), proton nuclear magnetic resonance spectroscopy $\left({ }^{1} \mathrm{H} N M R\right)$, elemental analysis, and charge density analysis methods confirmed that the anionic and cationic monomers were successfully grafted onto the lignin. The grafting ratios of AA and DMC monomer in the lignin-DMC-AA copolymer were $62.4 \%$ and $51.3 \%$, respectively. The application of lignin-DMC-AA copolymer as a paper additive for enhancing the physical properties of paper sheets was studied in the papermaking industry. The results indicated that the copolymer had a maximum increase in physical strength at around $2 \mathrm{wt} \%$ lignin-DMC-AA. The amount absorbed on the fibers was $18.5 \mathrm{mg} / \mathrm{g}$, and the retention of the lignin-DMC-AA copolymer was over $90 \%$.
\end{abstract}

Keywords: Softwood kraft lignin; Amphoteric lignin copolymer; Paper additive; Physical properties

Contact information: a: State Key Laboratory of Biobased Material and Green Papermaking, Key Laboratory of Pulp \& Paper Science and Technology of Shandong Province/Ministry of Education, Qilu University of Technology (Shandong Academy of Sciences), Jinan 250353, China; $b$ : Shandong Guanghua Paper Co.Ltd., Feixian, 273401,China; c: The Laboratory of Soft Materials \& Green Chemistry, Departments of Chemistry, Wood \& Paper Science, North Carolina State University, Raleigh, NC 27695, USA; d: Chemical Engineering Department, Lakehead University, Thunder Bay, ON, Canada; Corresponding authors: kfgwsj1566@163.com (F. Kong); nancy5921@163.com (S.Wang)

\section{INTRODUCTION}

Lignin is a heterogeneous and amorphous polymer that constitutes a large part of the cell wall, making it the second largest biomass after cellulose (Saito et al. 2012; Marino et al. 2016). Lignin accounts for 15 to $35 \%$ of the cell walls in terrestrial plants, which is generally considered a waste for low-value applications (Kai et al. 2016; Banu et al. 2019). Some chemical modifications can alter the properties of lignin and make it have high value utilization to fully realize its potential (Fang et al. 2010; Gao et al. 2019; Hajirahimkhan et al. 2019). These chemical modifications give lignin better miscibility over other polymeric matrices, thus improving the performance of lignin-based composites (Wang et al. 2011; Thakur et al. 2014; Liu et al. 2015).

Low-cost lignin has high carbon content, high thermal stability, biodegradability (Triwulandari et al. 2019), antioxidant activity, and favorable stiffness (Ten and Vermerris 2015; Thakur and Thakur 2015; Li et al. 2019b). These attributes have attracted a large number of researchers. Lignin-based resin was prepared with kraft lignin and glycerol to replace formaldehyde-based adhesives (Li et al. 2018). Meister et al. (2010) successfully 
prepared the lignin graft copolymer, which had a good effect as a mud thinner for drilling operations. Cai et al. (2017) successfully synthesized amphoteric lignin surfactant (SLQA) through the quaternization of sulfonated lignin, which could enhance the enzymatic hydrolysis of lignocellulose. Wang et al. (2016) developed a soda lignin-acrylamide copolymer, which can significantly enhance the physical properties of paper. Previously, the effects of three different lignin polymers as a paper dry-strength additive on pulp properties were studied (Liu et al. 2018). However, the amount absorbed on the fibers and the retention of lignin copolymer have not yet been studied. Moreover, it is rare to use lignin-based materials as paper additives in the paper industry according to current research (Wang et al. 2016).

In this study, amphoteric lignin copolymer was prepared by free radical polymerization using softwood kraft lignin as raw material, which can be used to improve the paper's physical properties as a strengthening agent. The main objectives were as follows: (1) production of an amphoteric lignin copolymer and analysis characterization through various analytical techniques; (2) Analysis of amphoteric lignin copolymer as a strengthening agent to improve the paper's physical properties. Additionally, the physical properties of the paper sheets were determined to measure the tensile, tear, and burst indices. The absorption of the amphoteric lignin copolymer on the pulp fibers was measured by a polyelectrolyte titration method after retention experiments for doses of 0.5 to $3 \%$ amphoteric lignin copolymer relative to pulp.

\section{EXPERIMENTAL}

\section{Materials}

Kraft pulping black liquor was used to produce softwood kraft lignin by an acid precipitation process (Kim 2015). Methacryloxyethyltrimethyl ammonium chloride (DMC) and acrylic acid (AA) were used as the grafting monomer as received from SigmaAldrich (Beijing, China). Potassium persulfate (KPS) as an initiator reagent was purchased from Sigma-Aldrich and used without further purification. Anionic polyvinyl sulfate (PVSK) and cationic polydiallyldimethylammonium chloride (PDADMAC) (Macklin, Shanghai, China) standard samples were diluted in ultrapure water. The alkaline peroxide mechanical pulp (APMP) was obtained from Shandong Sun Paper Industry (Jining, China).

\section{Preparation of Amphoteric Lignin Copolymer}

The preparation of amphoteric lignin copolymer was completed using DMC and AA as monomers, according to the earlier method by Liu et al. (2018). Here, $1 \mathrm{~g}$ of lignin was dispersed in $40 \mathrm{~mL}$ of ultrapure water and stirred at $400 \mathrm{rpm}$. Then, $\mathrm{NaOH}$ solution $(0.1 \mathrm{M})$ was used to adjust the $\mathrm{pH}$ of lignin solution to 11 . The lignin solution was heated to $75^{\circ} \mathrm{C}$ for $30 \mathrm{~min}$, and then the $\mathrm{pH}$ was adjusted to 4 using sulfuric acid $(0.1 \mathrm{M})$. Nitrogen was used for $30 \mathrm{~min}$ to remove oxygen from the solution, and a certain amount of KPS was added as an initiator. After $10 \mathrm{~min}$, the DMC monomer was added dropwise to the solution, and then the AA monomer was added to the solution. The copolymerization reaction of lignin with anionic and cationic monomers was carried out at $75^{\circ} \mathrm{C}$ for $3 \mathrm{~h}$. Next, the lignin solution was cooled, and ethanol/water $(80 \mathrm{vol} \%)$ was added to precipitate the amphoteric lignin copolymer. The precipitate was washed twice with ethanol/water $(80 \mathrm{vol} \%)$ and dried at $105{ }^{\circ} \mathrm{C}$ to produce a purified amphoteric lignin copolymer (lignin-DMC-AA copolymer). 


\section{Analytical Methods}

FTIR analysis

The lignin and lignin-DMC-AA copolymer samples were investigated using a Fourier transform infrared spectrophotometer (FTIR, Bruker VERTEX70; Bruker, Karlsruhe, Germany). Here, a $5 \mathrm{mg}$ sample of lignin and lignin-DMC-AA copolymer was used and recorded with 32 scans in transmittance mode.

\section{${ }^{1} H$ NMR analysis}

The proton nuclear magnetic resonance $\left({ }^{1} \mathrm{H}-\mathrm{NMR}\right)$ spectroscopy analysis of lignin and lignin-DMC-AA copolymer samples used a nuclear magnetic resonance (NMR) spectrometer (Bruker AVANCE II $400 \mathrm{MHz}$; Bruker, Karlsruhe, Germany). Approximately $10 \mathrm{mg}$ of the lignin and lignin-DMC-AA copolymer sample were dissolved in $\mathrm{D}_{2} \mathrm{O}$ and recorded over 32 scans.

\section{Thermal analysis}

The thermal analysis of lignin and lignin-DMC-AA copolymer samples was performed using a thermogravimetric analyzer (TGA Q50; TA, New Castle, DE, USA). Samples of 3 to $10 \mathrm{mg}$ lignin and lignin-DMC-AA copolymer were studied using nitrogen as protective gas from 50 to $600{ }^{\circ} \mathrm{C}$ at $10{ }^{\circ} \mathrm{C} / \mathrm{min}$.

\section{Elemental analysis}

Elemental analysis of lignin and lignin-DMC-AA copolymer samples were measured using an elemental analyzer (Vario EL III; Elementar, Hanau, Germany). Two to five samples of lignin and lignin-DMC-AA copolymer samples were used while the detection temperature was raised to $1150{ }^{\circ} \mathrm{C}$.

\section{Charge density analysis}

Approximately $20 \mathrm{mg}$ of lignin and lignin-DMC-AA copolymer samples were dissolved in a certain amount of ultra-pure water, and ultrasonicated at $30{ }^{\circ} \mathrm{C}$ for $1 \mathrm{~h}$. A particle charge detector (PCD 04; Mutek, Berlin, Germany) was performed to measure the charge density of the lignin solution with 0.001 M PDADMAC and PVSK standard solutions.

\section{Molecular weight analysis}

Approximately $5 \mathrm{mg}$ of lignin and lignin-DMC-AA copolymer samples were dissolved in $\mathrm{NaNO}_{3}$ solution $(0.1 \mathrm{M})$ at $35^{\circ} \mathrm{C}$ and continuously stirred at $500 \mathrm{rpm}$ for 36 $\mathrm{h}$. Then, $0.2-\mu \mathrm{m}$ nylon filters were used to filter the sample solutions, which was used to determine the lignin molecular weight by gel permeation chromatography (LC-20AD; Shimadzu, Tokyo, Japan). The chromatographic columns of PolyAnalytic PAA 203 and PAA 206 were used at $35{ }^{\circ} \mathrm{C}$, while $\mathrm{NaNO}_{3}$ solution $(0.1 \mathrm{M})$ was considered as the sample solvent and eluent. The flow rate of the sample solution was set to $0.50 \mathrm{~mL} / \mathrm{min}$.

\section{Grafting ratio}

The grafting ratio of lignin-DMC-AA copolymer sample was identified using Eq. 1 according to the previous calculation method (Wang et al. 2015),

$$
\text { Grafting ratio }=\left(N / 14 \times M_{\mathrm{w}}(\mathrm{DMC})\right) /\left(100-N / 14 \times M_{\mathrm{w}}(\mathrm{DMC})\right) \times 100
$$


where $N$ is the nitrogen content of samples (wt\%), and $M_{\mathrm{w}}(\mathrm{DMC})$ is the molecular weight of DMC (207.7 g/mol).

The carboxylate group content of lignin-DMC-AA copolymer sample was measured using an automatic potentiometer (905 Titrado; Metrohm, Berne, Switzerland). A sample of $1 \mathrm{~g}$ of lignin and lignin-DMC-AA copolymer was dissolved in $100 \mathrm{~mL}$ of ultrapure water and ultrasonicated for $30 \mathrm{~min}$, and then the $\mathrm{pH}$ value of the sample solution was adjusted to 10.5. Finally, the sample solution was titrated dropwise with the cationic surfactant to measure the carboxylate content of the sample. The grafting ratio was calculated using Eq. 2 (Bayazeed et al. 1989),

$$
\text { Grafting ratio }=\left(C \times M_{\mathrm{w}}(\mathrm{AA})\right) /\left(1-C \times M_{\mathrm{w}}(\mathrm{AA})\right) \times 100
$$

where $C$ is the total carboxylate group content $(\mathrm{mmol} / \mathrm{g})$, and $M_{\mathrm{w}}(\mathrm{AA})$ is the molecular weight of AA $(72 \mathrm{~g} / \mathrm{mol})$.

\section{Performance Assessments of Amphoteric Lignin Copolymer as Strengthening Agent}

The performance of lignin-DMC-AA copolymers as a strengthening additive was evaluated using APMP (a chemi-mechanical pulp used in making most kinds of paper). In this experiment, the lignin-DMC-AA copolymer sample was first dissolved in ultrapure water by stirring the sample for $2 \mathrm{~h}$ at $30{ }^{\circ} \mathrm{C}$. From 0 to $3 \mathrm{wt} \%$ dosage of lignin-DMC-AA copolymer were then added to the $1 \%$ pulp slurry, respectively. Before formation of the paper sheets, the pulp slurry containing lignin-DMC-AA copolymer was continuously stirred at $1500 \mathrm{rpm}$ for $5 \mathrm{~min}$. Formed paper sheets were dried at $97{ }^{\circ} \mathrm{C}$ for $7 \mathrm{~min}$. Paper sheets were tested for tensile and tear indices with a grammage of $60 \mathrm{~g} / \mathrm{m}^{2}$; burst index and the internal bond strength were tested with a grammage of $100 \mathrm{~g} / \mathrm{m}^{2}$. Before testing the physical strength properties of the paper, the paper sheet was held at $23{ }^{\circ} \mathrm{C}$ and $50 \%$ humidity for $24 \mathrm{~h}$ (Wang et al. 2016). After drying, the tensile, burst, and tear strengths, brightness, as well as the internal bonding strength of the handsheets, were measured according to the TAPPI T494 om-88 (1988), TAPPI T403 om-91 (1991), TAPPI T414 om88 (1988), TAPPI T452 om-92 (1992), and TAPPI T569 om-14 (1996) standards, respectively. All data described here were the average value of three repetitions.

\section{Absorption of Lignin-DMC-AA Copolymer on the Pulp Fibers}

For the absorption measurements, $5 \mathrm{~g}$ of pulp was dispersed in water at high speed, and 0 to 3\% lignin-DMC-AA copolymer was added for production of paper sheets. The pulp and the lignin-DMC-AA copolymer (total volume $1 \mathrm{~L}$ ) interacted with each other for 15 min under stirring conditions and then underwent dehydration treatment. After dehydration, the filtrate was titrated with PCD for charge titration. The content of ligninDMC-AA copolymer in the filtrate was calculated according to an appropriate standard curve. These were created according to the work on the cationic xylan copolymer (Deutschle et al. 2014).

\section{Lignin-DMC-AA Copolymer Retention}

The amount of nitrogen in the paper with different amounts of lignin polymer was determined via elemental analysis. The lignin-DMC-AA copolymer retention was calculated according to Eq. 3,

$$
\text { Retention }=N \times M /\left(N_{\mathrm{o}} \times M_{\mathrm{o}}\right) \times 100 \%
$$


where $N$ is the nitrogen content of paper (wt $\%), N_{\mathrm{o}}$ is the nitrogen content of lignin-DMCAA copolymer (wt $\%), M$ is the quality of the paper $(\mathrm{g})$, and $M_{\mathrm{o}}$ is the addition of the ligninDMC-AA copolymer (g).

\section{RESULTS AND DISCUSSION}

\section{Preparation of the Amphoteric Lignin Copolymer}

The reaction mechanisms of lignin, DMC, and AA are shown in Fig. 1. The KPS was added to the lignin solution as an initiator, resulting in lignin free radicals on the phenolic hydroxyl group. Moreover, the alkenyl groups of the DMC and AA monomers have high activity and can generate monomer-free radicals.

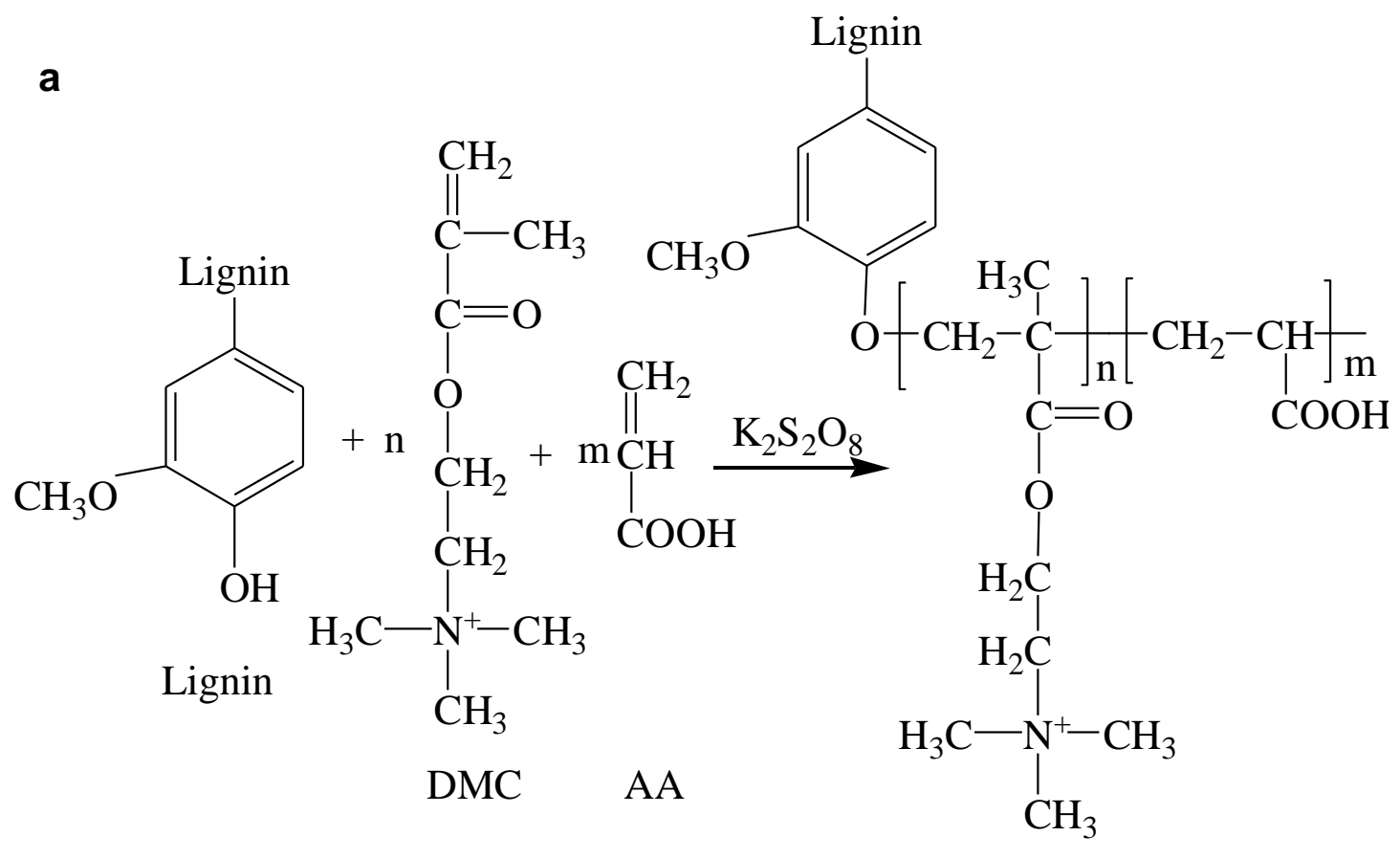

b<smiles></smiles>

$\mathrm{DMC}$<smiles>CCCC(C)(CC)C(=O)OCC[N+](C)(C)C</smiles>

PDMC 


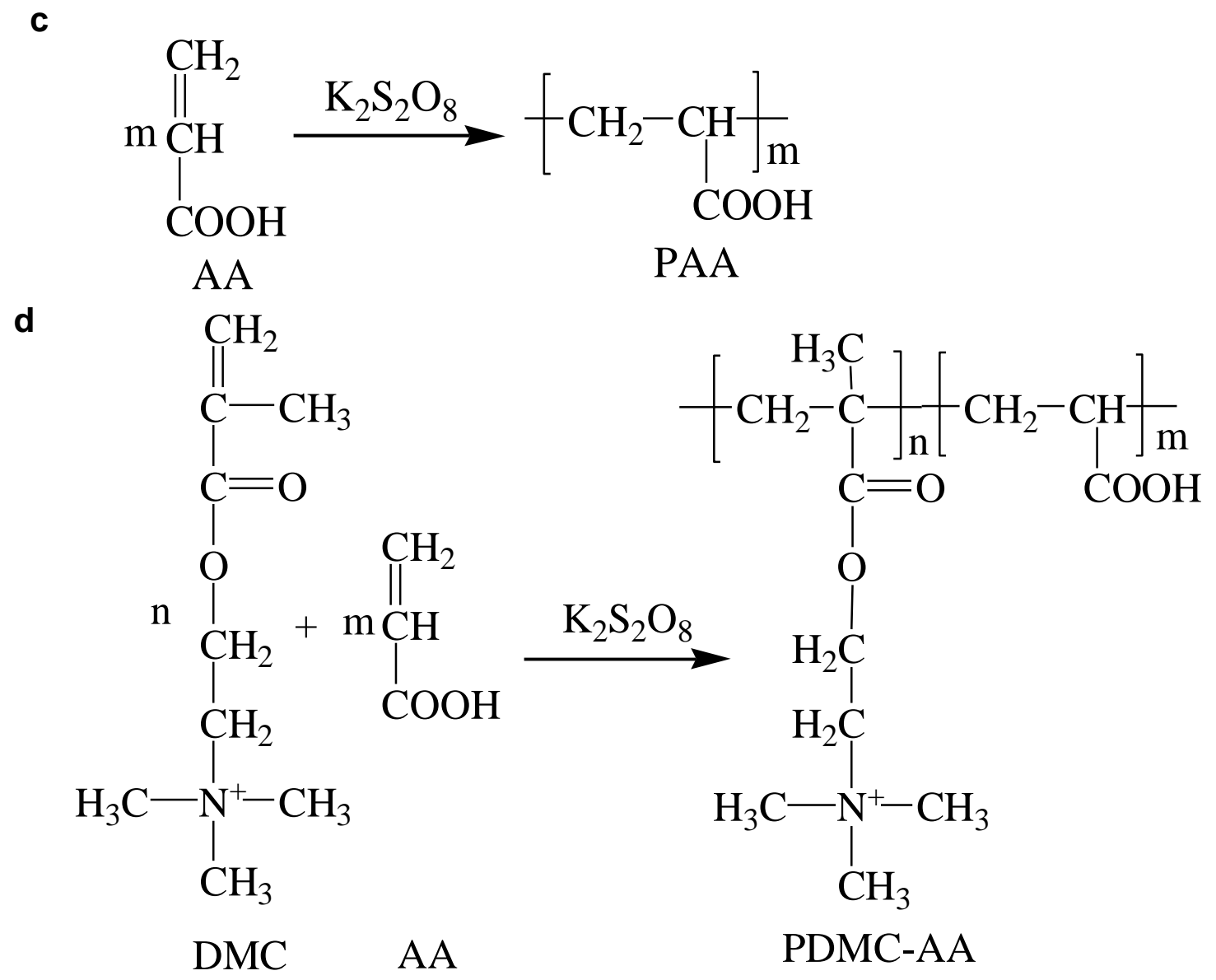

Fig. 1. Mechanism of the copolymerization of lignin with $D M C$ and $A A$ monomers (a: lignin-DMCAA; b: PDMC; c: PAA; and d: PDMC-AA)

These active free radicals become receptors for lignin free radicals, leading to the chain initiation of the amphoteric lignin copolymers (lignin-DMC-AA) (Wang et al. 2015). Furthermore, the above reaction was accompanied by side reactions to produce homopolymers of PDMC, PAA, and PDMC-AA.

\section{FTIR Analysis}

The FTIR spectra of the lignin and amphoteric lignin copolymer are shown in Fig. 2. The strong peak at $3440 \mathrm{~cm}^{-1}$ was assigned to the $\mathrm{O}-\mathrm{H}$ of the lignin and amphoteric lignin copolymer (Yu et al. 2016; Bian et al. 2018; Li et al. 2019a). The three absorption peaks at $1612 \mathrm{~cm}^{-1}, 1514 \mathrm{~cm}^{-1}$, and $1456 \mathrm{~cm}^{-1}$ are attributed to the aromatic skeletal vibrations from lignin and amphoteric lignin copolymer (Santos et al. 2012; Zhang et al. 2017). The peak at $2938 \mathrm{~cm}^{-1}$ originated from the $\mathrm{C}-\mathrm{H}$ stretching vibration (Konduri et al. 2015; Sarma et al. 2018). The absorption bands at $1219 \mathrm{~cm}^{-1}$ and $1121 \mathrm{~cm}^{-1}$ are assigned to the $\mathrm{C}-\mathrm{O}$ and $\mathrm{C}-\mathrm{H}$ stretching of the guaiacyl unit (Kong et al. 2015). The two peaks at $1716 \mathrm{~cm}^{-1}$ and $961 \mathrm{~cm}^{-1}$ were attributed to the $\mathrm{C}=\mathrm{O}$ (DMC and AA) and quaternary ammonium group (DMC), respectively (Wang et al. 2015). These peaks indicated that the amphoteric lignin copolymer had been successfully prepared. 


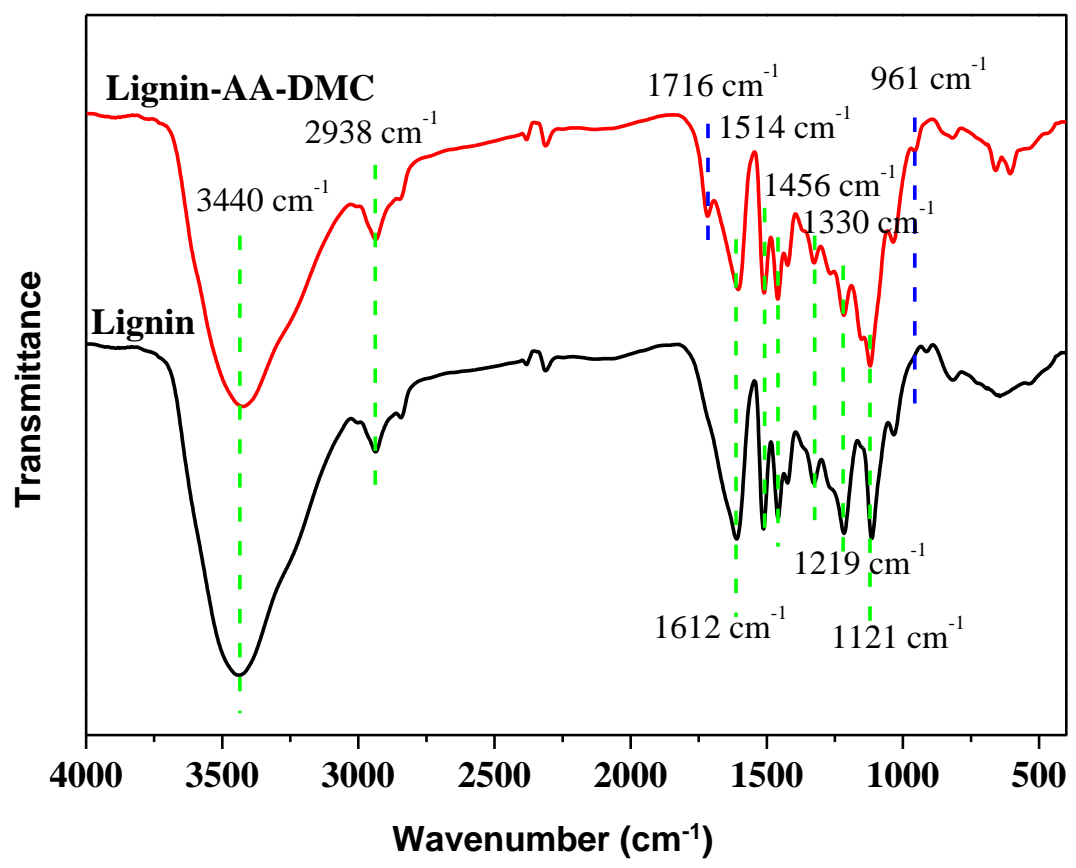

Fig. 2. FTIR spectra of lignin and amphoteric lignin copolymer (lignin-DMC-AA)

\section{${ }^{1} \mathrm{H}$ NMR Analysis}

The ${ }^{1} \mathrm{H}$ NMR spectra of the lignin and amphoteric lignin copolymer are shown in Fig. 3.

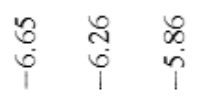

\section{Lignin}

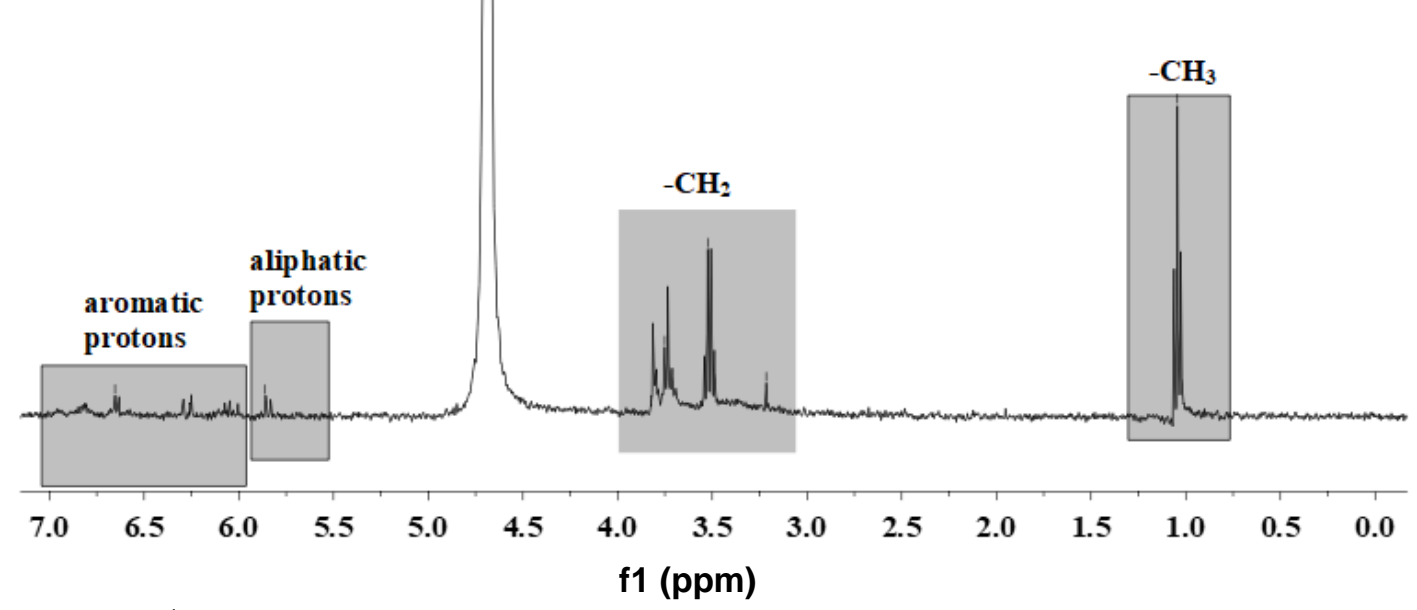

Fig. 3. A) ${ }^{1} \mathrm{H}-\mathrm{NMR}$ spectra of lignin 


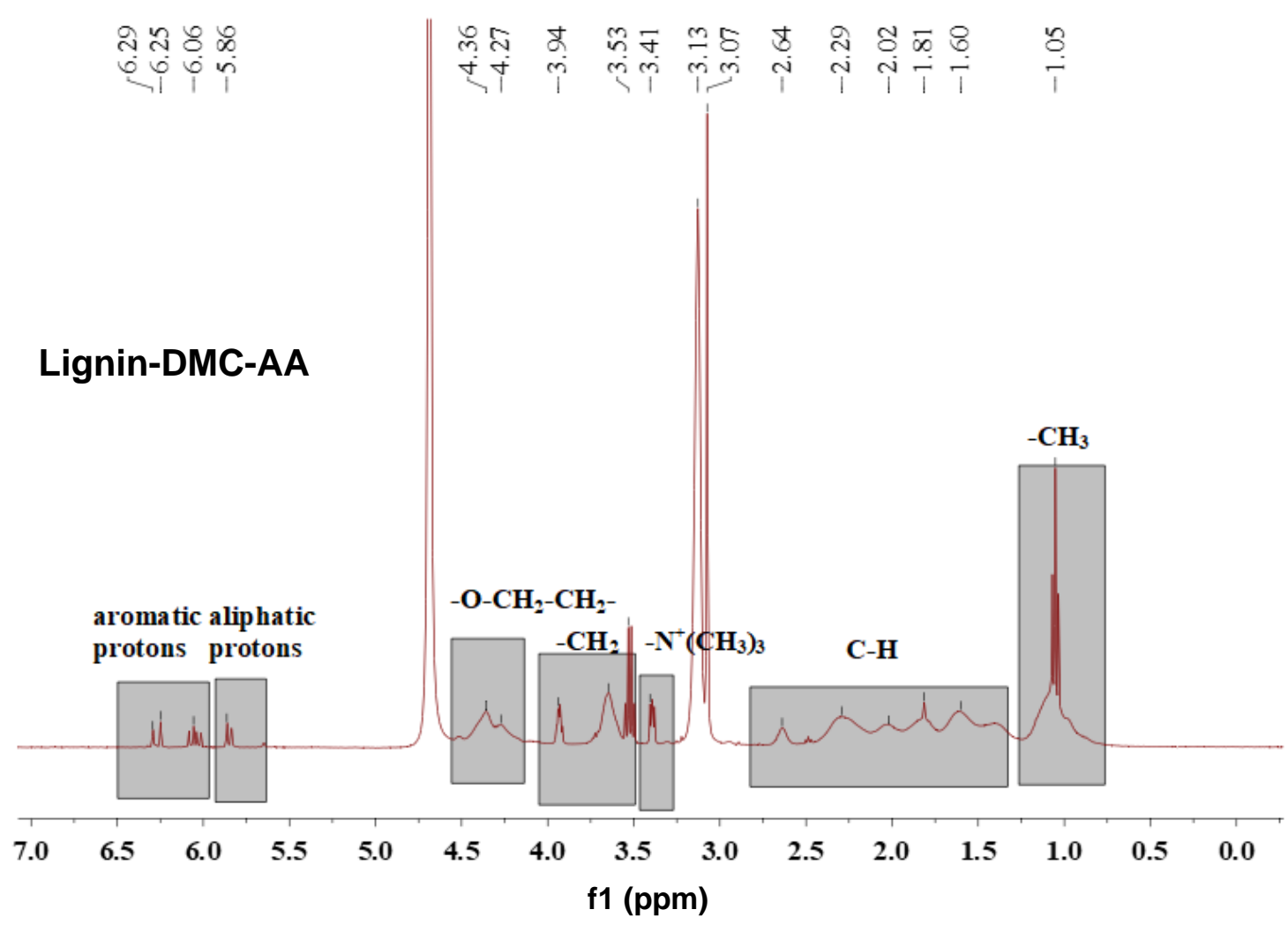

Fig. 3. B) ${ }^{1} \mathrm{H}-\mathrm{NMR}$ spectra of amphoteric lignin copolymer (lignin-DMC-AA)

The peaks at 6.0 to $7.0 \mathrm{ppm}$ are mainly due to aromatic protons, and the peaks at 5.1 to $5.9 \mathrm{ppm}$ are due to aliphatic protons. The peaks at 3.0 to $4.0 \mathrm{ppm}$ originate from the methoxyl groups of lignin and amphoteric lignin copolymer (Li et al. 2017); the peak at $3.2 \mathrm{ppm}$ is attributed to the $-\mathrm{CH}_{2}$ structure from lignin and amphoteric lignin copolymer. The peaks appearing from 0.9 to $1.1 \mathrm{ppm}$ originate from the $-\mathrm{CH}_{3}$ structure from lignin and amphoteric lignin copolymer (Nagy et al. 2010). The peaks at 4.5 to $5.0 \mathrm{ppm}$ are attributed to the solvent of the lignin and amphoteric lignin copolymer $\left(\mathrm{D}_{2} \mathrm{O}\right)$.

Relative to the spectrum of lignin, the characteristic signal at $3.4 \mathrm{ppm}$ can be attributed to $-\mathrm{N}^{+}\left(\mathrm{CH}_{3}\right)_{3}$ protons, and the characteristic signals near $3.9 \mathrm{ppm}$ and $4.3 \mathrm{ppm}$ are assigned to the methylene proton $\left(-\mathrm{O}-\mathrm{CH}_{2}-\mathrm{CH}_{2}-\right)$ from the DMC monomer of the amphoteric lignin copolymer ( $\mathrm{Li}$ et al. 2011). The peaks from 1.4 to $2.2 \mathrm{ppm}$ originate from $\mathrm{C}-\mathrm{H}$, and the peak at $2.6 \mathrm{ppm}$ is assigned to the hydroxyl end from the AA monomer of the amphoteric lignin copolymer (Witono et al. 2013). The above results indicated that the amphoteric lignin copolymer was prepared.

\section{Thermogravimetric Analysis}

The lignin and lignin-DMC-AA copolymer samples were analyzed using nitrogen as protective gas, and results are shown in Fig. 4. The weight of lignin and lignin-DMCAA copolymer samples decreased with increased temperature from 50 to $100{ }^{\circ} \mathrm{C}$, which was due to the loss of moisture (Ünlü et al. 2015). The thermal characteristics of lignin and lignin-DMC-AA copolymer were analyzed. The main degradation temperature of lignin weight ranged from 250 to $500{ }^{\circ} \mathrm{C}$. The temperature range of amphoteric lignin copolymer 
samples was 200 to $500{ }^{\circ} \mathrm{C}$. The maximum degradation rate of lignin and amphoteric lignin copolymer was slightly different, which is represented by $T_{\max }$ (maximum weight loss) at 385 and $397{ }^{\circ} \mathrm{C}$, respectively. The lignin remained approximately $40 \mathrm{wt} \%$; lignin-DMCAA copolymer remained approximately $30 \mathrm{wt} \%$. The above analysis showed that some chemical modifications lead to a certain degree of reduction in the thermal stability of the final product, which was contributed to the degradation of the new access group described in previous studies (Kong et al. 2015; Baniasad and Ghorbani 2016; Liu et al. 2018).

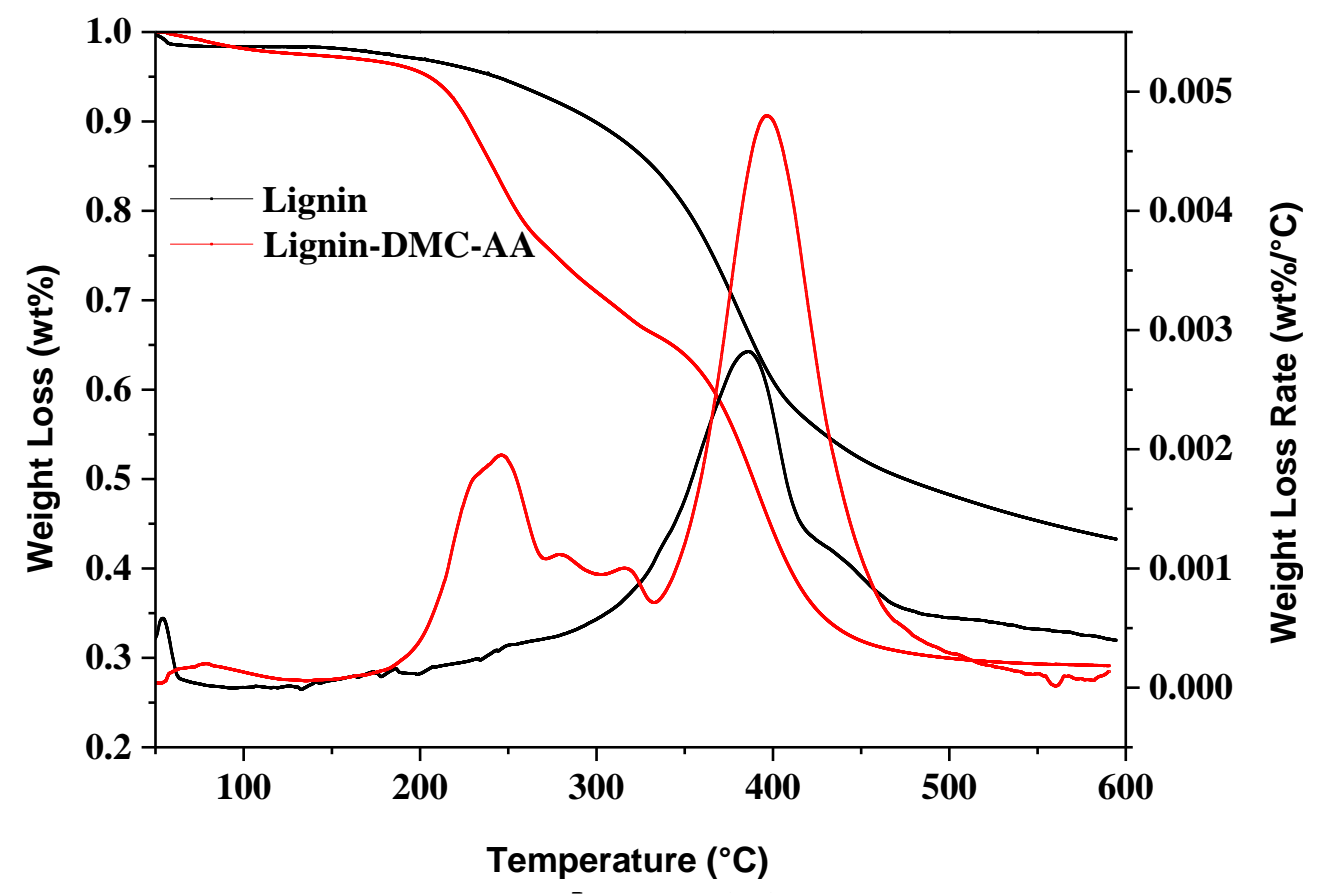

Fig. 4. Weight loss and weight loss rate of lignin and lignin-DMC-AA copolymer

\section{Properties of Lignin and Lignin-DMC-AA Copolymer}

The properties of the lignin and lignin-DMC-AA copolymer are shown in Table 1.

Table 1. Properties of Lignin and Lignin-DMC-AA Copolymer

\begin{tabular}{|c|c|c|}
\hline Samples & Lignin & Lignin-DMC-AA \\
\hline $\mathrm{C}(\mathrm{wt} \%)$ & 63.51 & 55.34 \\
\hline $\mathrm{H}(\mathrm{wt} \%)$ & 6.21 & 6.08 \\
\hline $\mathrm{O}(\mathrm{wt} \%)$ & 30.57 & 26.32 \\
\hline $\mathrm{N}(\mathrm{wt} \%)$ & 0.004 & 2.591 \\
\hline Molecular formula & $\mathrm{C}_{9} \mathrm{H}_{10.56} \mathrm{O}_{3.25}$ & $\mathrm{C}_{9} \mathrm{H}_{11.86} \mathrm{O}_{3.21} \mathrm{~N}_{0.36}$ \\
\hline $\mathrm{DMC}($ Graft ratio $(\%))$ & -- & 62.44 \\
\hline $\mathrm{AA}($ Graft ratio $(\%))$ & -- & 51.28 \\
\hline Charge density (mmol/g) & -0.002 & +0.946 \\
\hline$M_{\mathrm{n}}(\mathrm{g} / \mathrm{mol})$ & $1.725 \times 10^{4}$ & $3.647 \times 10^{5}$ \\
\hline$M_{\mathrm{w}}(\mathrm{g} / \mathrm{mol})$ & $2.600 \times 10^{4}$ & $4.256 \times 10^{5}$ \\
\hline$M_{\mathrm{w}} / \mathrm{Mn}$ & 1.51 & 1.17 \\
\hline
\end{tabular}


The charge densities of the lignin and lignin-DMC-AA copolymer dramatically increased from $-0.002 \mathrm{mmol} / \mathrm{g}$ to $+0.946 \mathrm{mmol} / \mathrm{g}$. The grafting ratios of AA and DMC in the lignin-DMC-AA copolymer were $62.4 \%$ and $51.3 \%$, respectively. Compared with unmodified lignin, lignin-DMC-AA copolymer had slightly higher weight average molecular weight $\left(M_{\mathrm{w}}\right)$ and number average molecular weight $\left(M_{\mathrm{n}}\right)$. The polydispersity $\left(M_{\mathrm{w}} / M_{\mathrm{n}}\right)$ of lignin and lignin-DMC-AA copolymer showed the change of molecular weight distribution. In addition, the $\mathrm{N}$ content of the lignin-DMC-AA copolymer remarkably increased from 0.004 to $2.591 \mathrm{wt} \%$ due to the amide group grafted onto the lignin. Therefore, the above analysis indicated that the copolymerization of DMC and AA monomer and lignin successfully changed the elemental content and charge density of lignin.

\section{Application of Lignin-DMC-AA Copolymer as a Strengthening Agent in Papermaking}

The results in Fig. 5 indicate that the lignin-DMC-AA copolymer can act as strength additive to improve the physical properties of paper sheets. As the dosage of lignin-DMCAA copolymer was increased, the tear, tensile, and burst indices increased remarkably. The increase in the paper strength was attributed to the formation of $\mathrm{H}$ bonding between the lignin-DMC-AA copolymer and cellulose fibers (Wang et al. 2016). At 2 wt $\%$ dosage of the lignin-DMC-AA copolymer, the maximum increases of $48.8 \%, 71.4 \%$, and $65.1 \%$, were obtained for burst, tensile, and tear indices, respectively. However, when the dosage of lignin-DMC-AA copolymer was further increased, the strength of the paper sheet decreased slightly. This decrease was due to an excess of lignin-DMC-AA copolymer, which lowered the retention of the lignin-DMC-AA copolymer on the fibers. This was due to the total amount of fiber remaining constant, while the positive and negative ions of lignin-DMC-AA copolymer were fixed to the surface of the fiber by adsorption, which was limited by the specific surface area of the fiber (Kong et al. 2018).

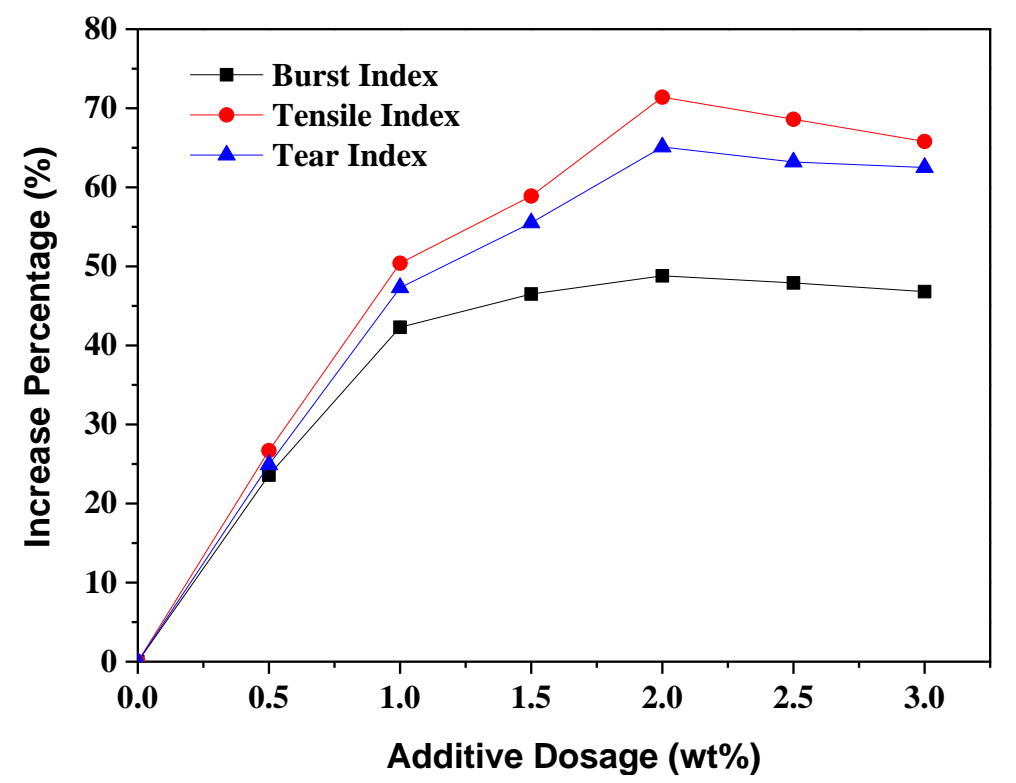

Fig. 5. Paper properties as function of lignin-DMC-AA copolymer dose 
The increase in the physical strength of paper sheets was attributed to the formation of an ionic bond between the amide groups of lignin-DMC-AA copolymer and negative charge of pulp fibers. It was also reported that the hydrogen bonding can be formed between the $\mathrm{OH}$ groups of starch and carboxyl $(\mathrm{COOH})$ groups of carboxymethyl cellulose (Tavares et al. 2020). Here, it would also be some hydrogen bonding development between the $\mathrm{COO}^{-}$groups of lignin-DMC-AA copolymer and $\mathrm{OH}$ groups of pulp fibers, which prompted the increase of internal bonding strength (see Table 2) and connections between fibers. The bonding development of lignin-DMC-AA copolymer and pulp fibers prompted the adsorption of lignin-DMC-AA copolymer on fibers. The lignin-DMC-AA copolymers were adsorbed between adjacent fibers (Fig. 6), such that the DMC and AA segments of the lignin-DMC-AA copolymer would bridge each other and remarkably enhance the bonding between the fibers (Wang et al. 2016).

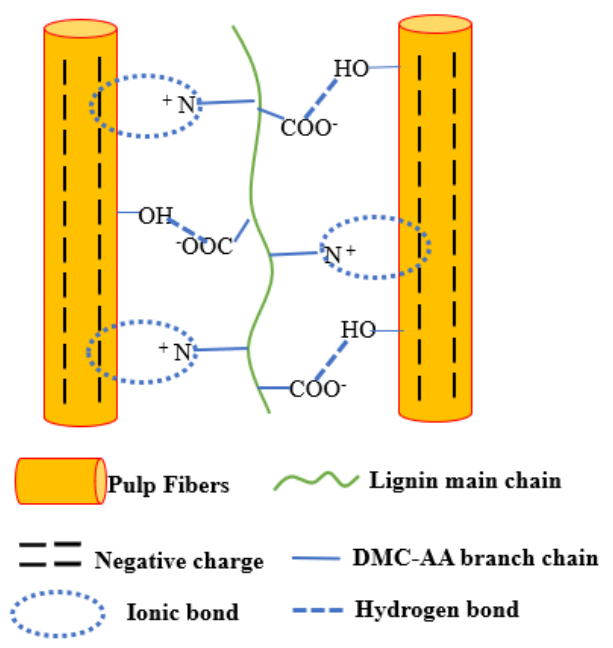

Fig. 6. Bridging of fibers by lignin-DMC-AA copolymer

Table 2 shows the changes in the internal bond strength and brightness of paper sheets using $2 \mathrm{wt} \%$ lignin and lignin-DMC-AA copolymer as a paper strengthening agent. The results indicated that the internal binding strengths of lignin-DMC-AA product increased by $64.9 \%$, compared with that of no additives and only using lignin as additives, which was due to the $\mathrm{H}$ bonds and ionic bonds generating between the lignin-DMC-AA copolymer and cellulose fibers. The brightness of paper without additives is $76 \%$ ISO, and the brightness of paper at additive dosages $2.0 \%$ drops slightly by $1 \%$ ISO, which would give a smaller decrease in the brightness of corrugated paper and cardboard paper.

Table 2. Internal Bond Strength and Brightness of the Paper

\begin{tabular}{|c|c|c|c|}
\hline Samples & $\begin{array}{c}\text { No } \\
\text { additives }\end{array}$ & Lignin & Lignin-DMC-AA copolymer \\
\hline Internal bonding strength $\left(\mathrm{J} / \mathrm{m}^{2}\right)$ & 180 & 185 & 305 \\
\hline Brightness $(\% \mathrm{ISO})$ & 76.0 & 75.6 & 75.0 \\
\hline
\end{tabular}

\section{Absorption of Lignin-DMC-AA Copolymer on the Pulp Fibers}

The amount of absorbed lignin-DMC-AA copolymer on the pulp fibers was calculated (mg/g; Fig. 7). Relative to the amount of additives, the absorption behavior of 
the fiber and the strength characteristics of the paper (Fig. 5) demonstrated the same increasing trend when the dosage of lignin-DMC-AA copolymer increased. With increasing amount of absorbed lignin-DMC-AA copolymer on the pulp fibers, the amount absorbed on the fibers reached a maximum of $18.5 \mathrm{mg} / \mathrm{g}$ at $2 \mathrm{wt} \%$ dosage, while the increase in paper strength plateaued. This was because the total amount of fiber remained constant, while the positive and negative ions of lignin-DMC-AA copolymer were fixed to the surface of the fiber by adsorption, which was limited by the specific surface area of the fiber (Kong et al. 2018).

When the addition amount of lignin exceeds $2 \%$, the increase in the cationic charge repulsion between the lignin polymers will result in a decrease in the amount of adsorption on the fiber. The ionic bond between the amide groups, negative charge of cellulose fibers, the hydrogen bonding development of lignin-DMC-AA copolymer, and negative charge of fibers balanced the electrostatic repulsion between the fiber and carboxyl group of ligninDMC-AA copolymer.

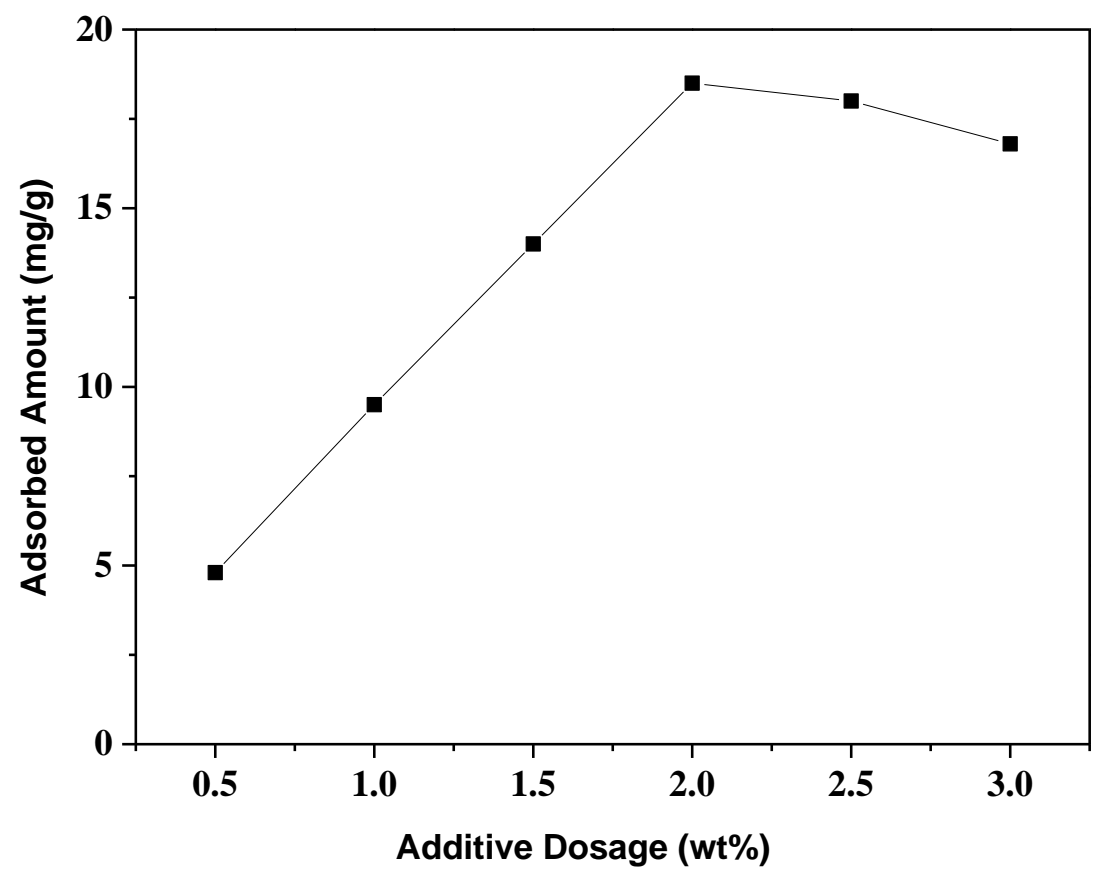

Fig. 7. Impact of lignin-DMC-AA copolymer dosage on fiber absorption

\section{Lignin-DMC-AA Copolymer Retention}

Figure 8 depicts the retention rate of paper on the lignin-DMC-AA copolymer sample, calculated as the total amount of lignin-DMC-AA copolymer added. When the dose of lignin-DMC-AA copolymer was less than $2 \%$, the retention of lignin-DMC-AA copolymer was more than $90 \%$. The lignin-DMC-AA copolymer retention continuously decreased with increasing dosage. Further increases up to $6 \%$ lignin-DMC-AA copolymer decreased the retention to $56 \%$. When the dosage of the lignin-DMC-AA copolymer was near $1 \%$, the retention of the lignin-DMC-AA copolymer sample was between $81 \%$ and $98 \%$. 


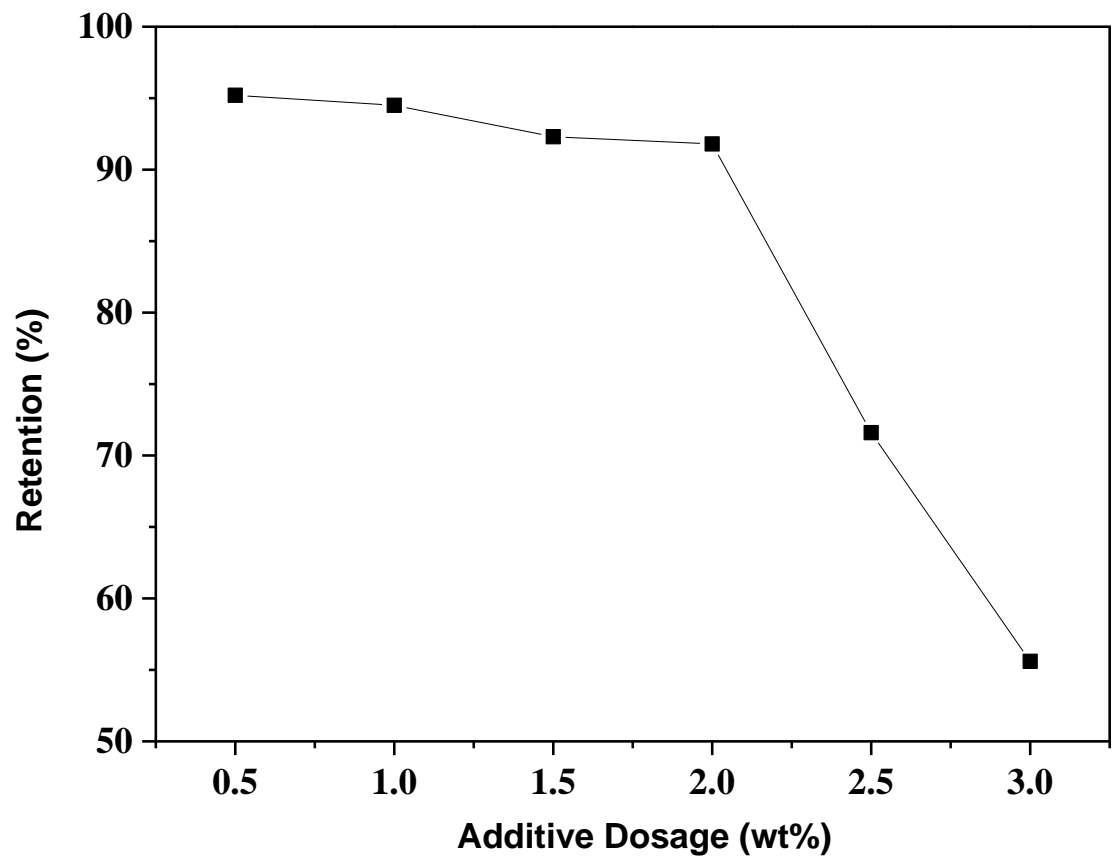

Fig. 8. Influences of lignin-DMC-AA copolymer dosage on the lignin-DMC-AA copolymer retention

\section{CONCLUSIONS}

1. In this study, cationic monomer (DMC) and anionic monomer (AA) were grafted onto softwood kraft lignin by free radical polymerization to prepare an amphoteric lignin copolymer.

2. The FTIR, ${ }^{1} \mathrm{H}$ NMR, elemental analysis and charge density analysis methods confirmed that the anion and cation monomers were successfully grafted onto softwood kraft lignin.

3. The grafting ratios of AA and DMC in the lignin-DMC-AA copolymer were $62.4 \%$ and $51.3 \%$, respectively. The application of lignin-DMC-AA copolymer as a paper additive enhanced the product's physical properties. At around $2 \mathrm{wt} \%$ addition of the lignin-DMC-AA, the burst, tensile, and tear indices of paper increased by $48.8 \%$, $71.4 \%$, and $65.1 \%$, respectively

4. The amount of the lignin-DMC-AA absorbed on the fibers was $18.5 \mathrm{mg} / \mathrm{g}$, and its retention was over $90 \%$.

\section{ACKNOWLEDGMENTS}

The authors appreciate the funding support from the National Natural Science Foundation of China (Nos. 31971605 and 31800499), the Shandong Key R\&D Program (No. 2019JZZY010407 and 2019JZZY010304), and the Natural Science Foundation of Shandong (Nos. ZR2017LEM009 and ZR2018BEM026). They also acknowledge the Key 
Research and Development Program of Shandong Province (No. 2017GSF17130), and the Foundation of Guangxi Key Laboratory of Clean Pulp \& Papermaking and Pollution Control of China (KF201717).

\section{REFERENCES CITED}

Baniasad, A., and Ghorbani, M. (2016). "Thermal stability enhancement of modified carboxymethyl cellulose films using $\mathrm{SnO}_{2}$ nanoparticles," International Journal of Biological Macromolecules 86, 901-906. DOI: 10.1016/j.ijbiomac.2016.02.029

Banu, J. R., Kavitha, S., Kannah, R. Y., Devi, T. P., Gunasekaran, M., Kim, S. H., and Kumar, G. (2019). "A review on biopolymer production via lignin valorization," Bioresource Technology 290, Article ID 121790. DOI:

10.1016/j.biortech.2019.121790

Bayazeed, A. D. S., Elzairy, M. R., and Hebeish, A. (1989). "Synthesis and application of new thickeners part I: Preparation of poly (acrylic acid)-starch graft copolymer," Starch - Stärke 41(6), 233-236. DOI: 10.1002/star.19890410608

Bian, H., Jiao, L., Wang, R., Wang, X., Zhu, W., and Dai, H. (2018). 'Lignin nanoparticles as nano-spacers for tuning the viscoelasticity of cellulose nanofibril reinforced polyvinyl alcohol-borax hydrogel," European Polymer Journal 107, 267274. DOI: 10.1016/j.eurpolymj.2018.08.028

Cai, C., Zhan, X., Zeng, M., Lou, H., Pang, Y., Yang, J., Yang, D., and Qiu, X. (2017). "Using recyclable $\mathrm{pH}$-responsive lignin amphoteric surfactant to enhance the enzymatic hydrolysis of lignocelluloses," Green Chemistry 19(22), 5479-5487 DOI: 10.1039/C7GC02571H

Deutschle, A. L., Römhild, K., Meister, F., Janzon, R., Riegert, C., and Saake, B. (2014). "Effects of cationic xylan from annual plants on the mechanical properties of paper," Carbohydrate Polymers 102(1), 627-635. DOI: 10.1016/j.carbpol.2013.12.016

Fang, R., Cheng, X., and Xu, X. (2010). "Synthesis of lignin-base cationic flocculant and its application in removing anionic azo-dyes from simulated wastewater," Bioresource Technology 101(19), 7323-7329. DOI: 10.1016/j.biortech.2010.04.094

Gao, C., Wang, S., Dong, X., Liu, K., Zhao, X., and Kong, F. (2019). "Construction of a novel lignin-based quaternary ammonium material with excellent corrosion resistant behavior and its application for corrosion protection," Materials 12(11), Article number 1776. DOI: 10.3390/ma12111776

Hajirahimkhan, S., Ragogna, P. J., and Xu, C. (2019). "Methacrylation of kraft lignin for UV-curable coatings: Process optimization using response surface methodology," Biomass and Bioenergy 120, 332-338. DOI: 10.1016/j.biombioe.2018.11.038

Kai, D., Tan, M. J., Chee, P. L., Chua, Y. K., Yap, Y. L., and Loh, X. J. (2016). "Towards lignin-based functional materials in a sustainable world," Green Chemistry 18(5), 1175-1200. DOI: 10.1039/c5gc02616d

Kim, S. J. (2015). "Preparation of a thermoplastic lignin-based biomaterial through atom transfer radical polymerization," Journal of Wood Chemistry and Technology 35(4), 251-259. DOI: 10.1080/02773813.2014.937006

Konduri, M. K., Kong, F., and Fatehi, P. (2015). "Production of carboxymethylated lignin and its application as a dispersant," European Polymer Journal 70, 371-383. DOI: 10.1016/j.eurpolymj.2015.07.028

Kong, F., Guo, Y., Liu, Z., Wang, S., and Lucia, L. A. (2018). "Synthesis of cationic xylan 
derivatives and application as strengthening agents in papermaking," BioResources 13(2), 2960-2976. DOI: 10.15376/biores.13.2.2960-2976

Kong, F., Parhiala, K., Wang, S., and Fatehi, P. (2015). "Preparation of cationic softwood kraft lignin and its application in dye removal," European Polymer Journal 67, 335345. DOI: 10.1016/j.eurpolymj.2015.04.004

Li, B., Yuan, Z., Schmidt, J., and Xu, C. (2019a). "New foaming formulations for production of bio-phenol formaldehyde foams using raw kraft lignin," European Polymer Journal 111, 1-10. DOI: 10.1016/j.eurpolymj.2018.12.011

Li, J., Yan, Q., Zhang, X., Zhang, J., and Cai, Z. (2019b). "Efficient conversion of lignin waste to high value bio-graphene oxide nanomaterials," Polymers 11(4), Article number 623. DOI: 10.3390/polym11040623

Li, J., Zhang, J., Zhang, S., Gao, Q., Li, J., and Zhang, W. (2017). "Fast curing bio-based phenolic resins via lignin demethylated under mild reaction condition," Polymers 9(9), Article number 428. DOI: 10.3390/polym9090428

Li, P., Hu, X., Wu, S., Chu, P. K., Yeung, K. W. K., and Xu, Z. (2011). “Cationic lanthanide luminescent copolymer: Design, synthesis and interaction with DNA," Journal of Macromolecular Science, Part A 48(10), 832-839. DOI: 10.1080/10601325.2011.603638

Li, R. J., Gutierrez, J., Chung, Y. L., Frank, C. W., Billington, S. L., and Sattely, E. S. (2018). "A lignin-epoxy resin derived from biomass as an alternative to formaldehyde-based wood adhesives," Green Chemistry 20(7), 1459-1466 DOI: 10.1039/C7GC03026F

Liu, W., Zhou, R., Zhou, D., Ding, G., Jie, M. S., Yue, C. Y., and Lu, X. (2015). "Ligninassisted direct exfoliation of graphite to graphene in aqueous media and its application in polymer composites," Carbon 83, 188-197. DOI: 10.1016/j.carbon.2014.11.036

Liu, Z., Xu, D., Xu, L., Kong, F., Wang, S., and Yang, G. (2018). "Preparation and characterization of softwood kraft lignin copolymers as a paper strength additive," Polymers 10(7), Article number 743. DOI: 10.3390/polym10070743

Marino, D. D., Stöckmann, D., Kriescher, S., Stiefel, S., and Wessling, M. (2016). "Electrochemical depolymerisation of lignin in a deep eutectic solvent," Green Chemistry 18(22), 6021-6028. DOI: 10.1039/c6gc01353h

Meister, J. J., Patil, D. R., and Channell, H. (2010). "Properties and applications of lignin-acrylamide graft copolymer," Journal of Applied Polymer Science 29(11), 3457-3477. DOI: 10.1002/app.1984.070291122

Nagy, M., Kosa, M., Theliander, H., and Ragauskas, A. J. (2010). "Characterization of $\mathrm{CO}_{2}$ precipitated Kraft lignin to promote its utilization," Green Chemistry 12(1), 3134. DOI: $10.1039 / \mathrm{b} 913602 \mathrm{a}$

Saito, T., Brown, R. H., Hunt, M. A., Pickel, D. L., Pickel, J. M., Messman, J. M., Baker, F. S., Keller, M., and Naskar, A. K. (2012). "Turning renewable resources into valueadded polymer: Development of lignin-based thermoplastic," Green Chemistry 14(12), 3295-3303. DOI: 10.1039/c2gc35933b

Santos, R. B., Capanema, E. A., Balakshin, M. Y., Chang, H., and Jameel, H. (2012). "Lignin structural variation in hardwood species," Journal of Agricultural and Food Chemistry 60(19), 4923-4930. DOI: 10.1021/jf301276a

Sarma, R., Islam, M. S., Running, M. P., and Bhattacharyya, D. (2018). "Multienzyme immobilized polymeric membrane reactor for the transformation of a lignin model compound," Polymers 10(4), Article number 463. DOI: 10.3390/polym10040463 
TAPPI T403 om-91 (1991). "Bursting strength of paper," TAPPI Press, Atlanta, GA, USA.

TAPPI T414 om-88 (1988). "Internal tearing resistance of paper (Elmendorf-type method)," TAPPI Press, Atlanta, GA, USA.

TAPPI T452 om-92 (1992). "Brightness of pulp, paper, and paperboard (directional reflectance at $457 \mathrm{~nm})$, , TAPPI Press, Atlanta, GA, USA.

TAPPI T494 om-88 (1988). "Tensile properties of paper and paperboard (using constant rate of elongation apparatus)," TAPPI Press, Atlanta, GA, USA.

TAPPI T569 om-14 (1996). "Internal bond strength (Scott type)," TAPPI Press, Atlanta, GA, USA.

Tavares, K. M., Campos, A., Luchesi, B. R., Resende, A. A., Oliveira, J. E., and Marconcini, J. M. (2020). "Effect of carboxymethyl cellulose concentration on mechanical and water vapor barrier properties of corn starch films," Carbohydrate Polymers 246, Article number 116521. DOI:10.1016/j.carbpol.2020.116521

Ten, E., and Vermerris, W. (2015). "Recent developments in polymers derived from industrial lignin," Journal of Applied Polymer Science 132(24), Article ID 42069. DOI: 10.1002/app.42069

Thakur, V. K., and Thakur, M. K. (2015). "Recent advances in green hydrogels from lignin: A review," International Journal of Biological Macromolecules 72, 834-847. DOI: 10.1016/j.ijbiomac.2014.09.044

Thakur, V. K., Thakur, M. K., Raghavan, P., and Kessler, M. R. (2014). "Progress in green polymer composites from lignin for multifunctional applications: A review," ACS Sustainable Chemistry 2(5), 1072-1092. DOI: 10.1021/sc500087z

Triwulandari, E., Ghozali, M., Sondari, D., Septiyanti, M., Sampora, Y., Meliana, Y., Fahmiati, S., Restu, W. K., and Haryono, A. (2019). "Effect of lignin on mechanical, biodegradability, morphology, and thermal properties of polypropylene/polylactic acid/lignin biocomposite," Plastics, Rubber and Composites 48(2), 82-92. DOI: 10.1080/14658011.2018.1562746

Ünlü, C. H., Kutlu, M., and Atıcı, O. G. (2015). "Mannich reaction of polysaccharides: Xylan functionalization in aqueous basic medium," Carbohydrate Polymers 127, 1927. DOI: 10.1016/j.carbpol.2015.03.024

Wang, J., Yao, K., Korich, A. L., Li, S., Ma, S., Ploehn, H. J., Iovine, P. M., Wang, C., Chu, F., and Tang, C. (2011). "Combining renewable gum rosin and lignin: Towards hydrophobic polymer composites by controlled polymerization," Journal of Polymer Science Part A: Polymer Chemistry 49(17), 3728-3738. DOI: 10.1002/pola.24809

Wang, S., Hou, Q., Kong, F., and Fatehi, P. (2015). "Production of cationic xylanMETAC copolymer as a flocculant for textile industry," Carbohydrate Polymers 124 , 229-236. DOI: 10.1016/j.carbpol.2015.02.015

Wang, S., Sun, Y., Kong, F., Yang, G., and Fatehi, P. (2016). "Preparation and characterization of lignin-acrylamide copolymer as a paper strength additive," BioResources 11(1), 1765-1783. DOI: 10.15376/biores.11.1.1765-1783

Witono, J. R., Marsman, J. H., Noordergraaf, I. W., Heeres, H. J., and Janssen, L. P. B. M. (2013). "Improved homopolymer separation to enable the application of ${ }^{1} \mathrm{H}$ NMR and HPLC for the determination of the reaction parameters of the graft copolymerization of acrylic acid onto starch," Carbohydrate Research 370, 38-45. DOI: 10.1016/j.carres.2013.01.017

Yu, C., Wang, F., Fu, S., Liu, H., and Meng, Q. (2016). "Laccase-assisted grafting of acrylic acid onto lignin for its recovery from wastewater," Journal of Polymers and 
the Environment 25, 1-8. DOI: 10.1007/s10924-016-0846-8

Zhang, S., Liu, L., Fang, G., Yan, N., Ren, S., and Ma, Y. (2017). "Hydrogenolysis and activation of soda lignin using [BMIM]Cl as a catalyst and solvent," Polymers 9(7), Article number 279. DOI: 10.3390/polym9070279

Article submitted: July 15, 2020; Peer review completed: September 12, 2020; Revised version received and accepted: October 21, 2020; Published: October 29, 2020.

DOI: 10.15376/biores.15.4.9625-9641 